\title{
Investigation of mechanical and micro structural properties of ST14 steel sheet joints by friction stir welding process
}

\section{Mahmoud Afshari ( $\nabla$ m.afshari@aut.ac.ir)}

Amirkabir University of Technology Department of Mechanical Engineering https://orcid.org/00000002-8556-4264

Hossein Norozi Foroushani

Amirkabir University of Technology Department of Mechanical Engineering

\section{Ehsan Salahshour Rad}

Malek Ashtar University of Technology Faculty of Materials Engineering

\section{Iraj Sattari Far}

Amirkabir University of Technology

Amirhossein Alavi

University of Birjand

\section{Original Article}

Keywords: FSW, ST14 steel, microstructure, tensile strength, hardness.

Posted Date: November 25th, 2020

DOl: https://doi.org/10.21203/rs.3.rs-113060/v1

License: (c) (1) This work is licensed under a Creative Commons Attribution 4.0 International License. Read Full License 


\section{Abstract}

High strength and ductility are considered as the superior features of ST14 steel, which have resulted in the extensive usage of this material in the automotive and aerospace industries. Friction stir welding (FSW) is one of the new methods of solid-state welding with preferable mechanical properties for joining steel components.

In this study, the mechanical and microstructural properties of $1.5 \mathrm{~mm}$ thick ST14 steel sheets in FSW process are investigated. The results revealed the highest tensile strength of $305 \mathrm{MPa}$ for the welded specimen at the rotational speed of $800 \mathrm{rpm}$ and linear speed of $80 \mathrm{~mm} / \mathrm{min}$. In addition, higher separation rate of the tungsten carbide particles from the tool as a result of higher heat input to the piece was realized from the metallographic test with the use of sample with rotational speed of $1000 \mathrm{rpm}$ and linear speed of $50 \mathrm{~mm} / \mathrm{min}$. Moreover, regarding the results of micro hardness test, an increased hardness to $115 \pm 1 \mathrm{HV}$ in the stirred zone (SZ) was acquired in this sample. Furthermore, the presence of the tungsten carbide particles were observed in this area.

\section{Introduction}

Friction stir welding (FSW) is regarded as one of the relatively novel solid-metal bonding methods. Today, FSW has found extensive applications in various industries such as shipbuilding, aerospace, automotive and rail, considering its superior advantages such as no requirement for consumables, desirable mechanical properties as well as high distortion reduction (Nandan et al. 2008; Jadhav, and Dalu 2014; Roldo and Vulić 2019).

In this method, a wear-resistant rotating tool with a specific geometry at the pin and shoulder penetrates the joint section of the connecting parts and moves along the connection path. According to the generated heat from the friction between the workpiece and the tool, the edge is softened and hence, the joint would be created by the material removal resulted from the tool rotation (Besharati-Givi and Asadi 2014; Pietras and Rams 2016). The schematic representation of this process is depicted in Fig. 1.

In recent years, several researches have been conducted in the field of FSW process. Reynolds et al. (2003) investigated the feasibility of bonding DH36 carbon steel sheets to 304 stainless steel sheets through the use of FSW process and declared the improved mechanical properties of the joints. Sahin et al. (2005) explored the influential parameters on bonding of the high speed steel sheets to the plain carbon steel by FSW. They obtained the highest tensile strength at the frictional pressure and time of $600 \mathrm{MPa}$ and 3.7 seconds, respectively. Ueji et al. (2006) performed FSW on three different types of plain low-carbon steels (annealed, cold worked and quenched) at different rotational speeds. Their results declared the wider modified area of the quenched specimen at the same rotational speed. Moreover, Meshram et al. (2013) expressed the bond toughness of Grade 250 steel sheets in the FSW process. The influential parameters on the transient temperature distribution in the friction welding of $304 \mathrm{~L}$ stainless steel were evaluated by Chansoria et al. (2015). They reported the increased temperature peak through 
the increase of tool rotation speed, decrease of travel speed as well as the increase of normal force and shoulder radius.

Regarding the extensive application of the ST14 steel in the industry besides the lack of sufficient information for strength of the welded joints of these steels, in this study, it is aimed to determine the appropriate welding parameters and mechanical properties of the welded piece.

\section{Experimental Procedure}

The current improvements in the material science as well as the numerous experimental investigations have led to the use of various tools with different geometries and materials in the FSW process of steels. Tungsten carbide was selected as the used material for the tool in this research. The geometrical parameters of the tool are shown in Table 1.

Table 1

Geometric parameters of the tool used for the welding process.

\begin{tabular}{|c|c|c|c|}
\hline $\begin{array}{l}\text { Diameter of the tool } \\
\text { shoulder)mm( }\end{array}$ & $\begin{array}{l}\text { Diameter of tool pin } \\
\text { )mm( }\end{array}$ & $\begin{array}{l}\text { Tool Pin } \\
\text { Length } \\
(\mathrm{mm})\end{array}$ & $\begin{array}{l}\text { Angle of tool shoulder cone } \\
\text { )degree( }\end{array}$ \\
\hline 14.2 & 3.9 & 1.3 & 5 \\
\hline
\end{tabular}

For this purpose, a ST14 steel sheet with the dimensions of $160 \times 80 \times 1.5 \mathrm{~mm}$ was utilized as the workpiece, which was bonded to other sheets with the help of a butt joint without any gaps. The analysis of the chemical composition for ST14 steel is given in Table 2.

Table 2

Chemical composition of ST14 steel (by weight percent).

\begin{tabular}{|lllll|}
\hline Element & $\mathrm{Fe}$ & $\mathrm{C}$ & $\mathrm{Si}$ & $\mathrm{Mn}$ \\
\hline$\% \mathrm{wt}$. & base. & 0.04 & 0.01 & 0.23 \\
\hline $\mathrm{P}$ & $\mathrm{Ni}$ & $\mathrm{Mo}$ & $\mathrm{Cu}$ & $\mathrm{V}$ \\
\hline 0.007 & 0.03 & 0.01 & 0.03 & 0.002 \\
$\mathrm{~W}$ & $\mathrm{Co}$ & $\mathrm{Al}$ & $\mathrm{Sn}$ & $\mathrm{Pb}$ \\
\hline 0.003 & 0.004 & 0.055 & 0.007 & 0.003 \\
\hline
\end{tabular}

A manual milling machine was implemented for the provision of the required rotational motion in the pins to connect the sheets. Moreover, a fixture with the dimensions of $600 \times 400 \times 2 \mathrm{~mm}$ was employed for 
fixing the sheets during the process. Furthermore, Talc powder was also used to prevent the possible adherence of the sheets to the fixture during the welding process.

Different levels of welding parameters, including the tool rotational speed and linear motion velocity were selected for the provision of various modes of joint mechanical properties in the FSW process. It should be noted that in all experiments, the tool deflection angle was considered to be the constant value of 2 degrees. The considered parameters level for different welding modes are represented in Table 3.

Table 3

Variable values for different welding states.

\begin{tabular}{|lll|}
\hline Sample no. & rotational speed (rpm) & linear motion speed $(\mathrm{mm} / \mathrm{min})$ \\
\hline 1 & 1000 & 50 \\
\hline 2 & 500 & 100 \\
\hline 3 & 1000 & 100 \\
\hline
\end{tabular}

For evaluation of the mechanical properties of the bonded sheets, the normal tensile tests were performed. The required specimens for these tests were prepared according to ASTME8 standard (Fig. 2).

Moreover, the metallographic tests were performed to investigate the microstructure of base metal (BM), weld metal, thermo-mechanically Affected Zone (TMAZ) and microstructural changes of the samples cross-sections. The surfaces of the specimens were grinded using silicon carbide sandpaper (80 to 3000 ) and then polished with 0.3-micron alumina powder. Then, the samples were etched with Nital solution containing $2 \%$ nitric acid and $98 \mathrm{ml}$ of alcohol for 30 seconds to reveal the microstructure of base metal and weld metal. Then, the microstructures of different welded zones were analyzed by Olympus optical microscopy (ck40m model) at different magnifications. The Buehler hardness tester was also used to measure the micro hardness of the specimens; while Vickers micro hardness test was performed for the determination of the hardness profile of the weld sections. The specimens were embedded perpendicularly with respect to the central welding line. For conducting the hardness test, the weight of $100 \mathrm{gr}$ was released from the distance of $0.75 \mathrm{~mm}$ with respect to the workpiece surface (center line in thickness). In addition, the tests on the specimens were conducted at the intervals of $1 \mathrm{~mm}$. The results of this experiment are presented as hardness profiles for all samples and provided in the results section.

\section{Results And Discussion}

\subsection{Investigation of the effects of welding parameters on tensile strength}

The results of the uniaxial tensile test on the joints as well as the failure location of the specimens are renrecented Tahle 4 Loading [MathJax]/jax/output/CommonHTML/fonts/TeX/fontdata.js 
Table 4

Results of uniaxial tensile test and location of joint failure.

\begin{tabular}{|lll|}
\hline Sample no. & Ultimate tensile strength of the joints $) \mathrm{MPa}($ & Location of failure \\
\hline 1 & 270 & Base Metal \\
\hline 2 & 91 & Weld metal \\
\hline 3 & 299 & Base Metal \\
\hline 4 & 305 & Base Metal \\
\hline
\end{tabular}

According to Table 4, in the rotational speed of $800 \mathrm{rpm}$ and linear speed of $80 \mathrm{~mm} / \mathrm{min}$, the sample (4) attains the highest tensile strength of $305 \mathrm{MPa}$, which is approximately $101 \%$ of the base metal.

\subsection{Microstructure analysis of ST14 welded steel joints}

The optical microscopy image of the 14ST base metal cross section is depicted in Fig. 3. According to this figure, the microstructure is mainly comprised of ferrite phase and an insignificant amount of pearlite phase due to low carbon content $(0.04 \%)$. The lever rule in the Fe-C diagram also confirms the presence of $98 \%$ ferrite phase and $2 \%$ pearlite phase in the structure.

The optical microscopy image of the cross-section for sample (4) is represented in Fig. 4. As it is clear, different zones with different properties can be seen at the junction, which is related to the generated heat and the resulted thermomechanical operations. Therefore, the growth of the ferrite grains is expected. On the other hand, rotation of the pin and shoulder in the Stirred Zone (SZ) results in performing the thermomechanical operations and the consequence recrystallization in the grains. The formed finer grains (up to 10-20 times), would lead to the enhanced mechanical properties of the joint. The TMAZ, which is located in the adjacency of SZ zone, is also affected by the heat and mechanical operations with the lower intensities compared to the SZ. The Heat Affected Zone (HAZ) that is located between the BM and TMAZ, is only influenced from the heat and no mechanical operations are performed in this area. As it is obvious from the figure, larger and more elongated grains compared to the BM are presented in this region.

For the sake of comparing the welding parameters, optical microscopic images for the cross section of the sample (1) are examined and depicted in Fig. 5.

The higher heat input to sample (1) is associated with the lower linear motion speed and higher rotational speed in this case. Moreover, the temperature of the tungsten carbide tool is also increased due to high friction. This phenomenon also results in the softening of the tool and removal of the tungsten carbide particles from the tool and entrance to the SZ. Consequently, the bonding properties would be affected and the strength would be reduced. Moreover, considering the high heat and the resultant grain growth in the $S Z$, the reduced hardness is expected. However, in contrast to our expectations, the results revealed 
the significant increase in the hardness of the area, which may be associated with the removal of tungsten carbide particles from the tool that is visible in the form of black particles.

\subsection{Survey hardness profile of ST14 welded joints}

The hardness profiles of the cross-sections for the welded specimens are given in Figs. 6-9.

The average hardness of the ST14 steel sheet is equal to 91.5 , which is related to the increased hardness of the weld metals compared to the base metal. The significant reduction of the grain size in the weld area is resulted from the microstructural changes during the welding process. As mentioned earlier, in sample (1), the hardness of the perturbation zone increased due to the separation of tungsten carbide particles from the tool and formation of iron and tungsten carbide. In sample (2), due to the low rotational speed and high speed of linear movement, the lack of sufficient heat in the desired area caused the turbulence between the two samples.

Moreover, the hardness is increased in the SZ region regarding the finer structure; however, due to the lack of sufficient perturbation, the sample is not robust enough.

In samples (3) and (4), despite the fine-grained structure in the SZ region due to thermomechanical operations, the hardness is increased. However, in further distances away from the central welding line, a gradual reduction in the hardness of the TMAZ and HAZ is realized.

\section{Conclusion}

In this study, the mechanical and microstructural properties of ST14 steel sheet joints through FSW process were investigated. The effect of different parameters on the tensile strength and hardness of the welded joint, including the linear motion velocity and rotational speed of the tool were evaluated. The obtained results were summarized as:

1- The maximum tensile strength of $305 \mathrm{MPa}$ for the ST14 steel sheet joints by FSW was obtained at the linear movement speed of $80 \mathrm{~mm} / \mathrm{min}$ and rotational speed of $800 \mathrm{rpm}$.

2- The hardness of the perturbed region was higher in the welded sheets compared to the base metal. On both sides of the weld line, the coarser grains would have resulted in the lower hardness of the HAZ in comparison with the base metal.

3- The obtained results from the different tensile and hardness tests revealed the significant influence of the frictional disturbance parameters (tool rotational speed and linear motion velocity in this study) on the quality and properties of the joint.

\section{References}

Nandan, R., DebRoy, T. and Bhadeshia, H.K.D.H., (2008). Recent advances in friction-stir welding-process, Loading [MathJax]/jax/output/CommonHTML/fonts/TeX/fontdata.js science, 53(6), pp.980-1023, 
doi:10.1016/j.pmatsci.2008.05.001.

Roldo, L. and Vulić, N., (2019), Friction Stir Welding for Marine Applications: Mechanical Behavior and Microstructural Characteristics of Al-Mg-Si-Cu Plates. Transactions on maritime science, 8(01), pp.75-83, doi: 10.7225/toms.v08.n01.008.

Jadhav, G.C. and Dalu, R.S., (2014), Friction Stir Welding-Process Parameters and its Variables: A Review. International Journal of Engineering and Computer Science, 3, pp.6325-6328.

Pietras, A. and Rams, B., (2016), FSW Welding of Aluminum Casting Alloys. Archives of Foundry Engineering, 16(2), pp.119-124, doi: 10.1515/afe-2016-0038.

Besharati-Givi, M.K. and Asadi, P., (2014), Advances in friction-stir welding and processing. 1 st Edition, Woodhead Publishing Series in Welding and Other Joining Technologies, Elsevier,

Mishra, R.S. and Ma, Z.Y., (2005), Friction stir welding and processing. Materials Science and Engineering Faculty Research \& Creative Works, 50(1-2), pp.1-78, doi: 10.1016/j.mser.2005.07.001.

Reynolds, A.P., Tang, W., Posada, M. and DeLoach, J., (2003), Friction stir welding of DH36 steel. Science and technology of welding and joining, 8(6), pp.455-460, doi: 10.1179/136217103225009125.

Sahin, M., (2005), Joining with friction welding of high-speed steel and medium-carbon steel. Journal of Materials Processing Technology, 168(2), pp.202-210, doi: 10.1016/j.jmatprotec.2004.11.015.

Ueji, R., Fujii, H., Cui, L., Nishioka, A., Kunishige, K. and Nogi, K., (2006), Friction stir welding of ultrafine grained plain low-carbon steel formed by the martensite process. Materials Science and Engineering: $A$, 423(1-2), pp.324-330, doi: 10.1016/j.msea.2006.02.038.

Meshram, S.D., Reddy, G.M. and Pandey, S., (2013), Friction stir welding of maraging steel (Grade-250). Materials \& Design, 49, pp.58-64, doi: 10.1016/j.matdes.2013.01.016.

Chansoria, P., Solanki, P. and Dasgupta, M.S., (2015), Parametric study of transient temperature distribution in FSW of 304L stainless steel. The International Journal of Advanced Manufacturing Technology, 80(5-8), pp.1223-1239, doi: 10.1007/s00170-015-7102-6.

\section{Figures}




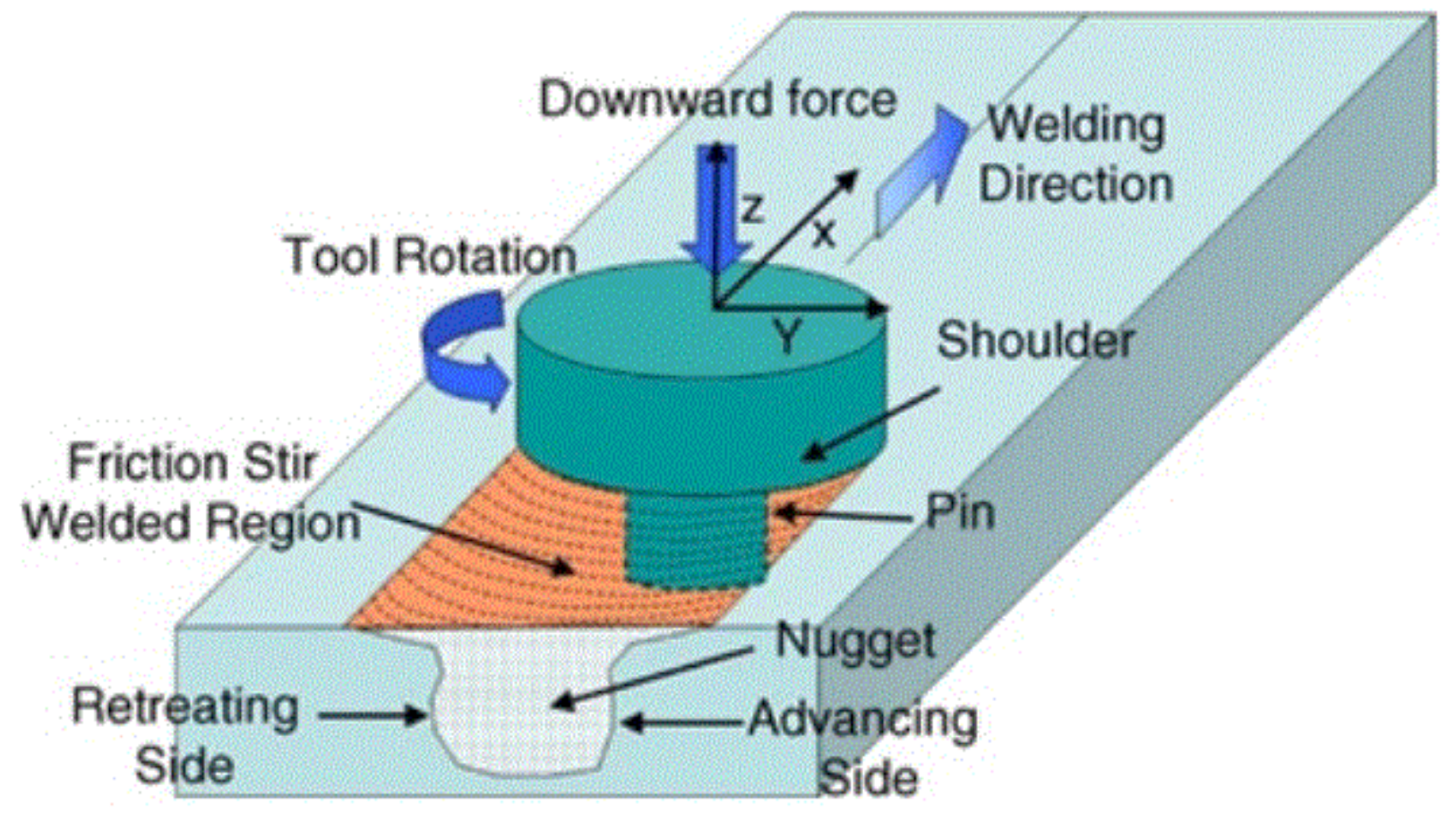

Figure 1

Schematic of the friction-welding process.

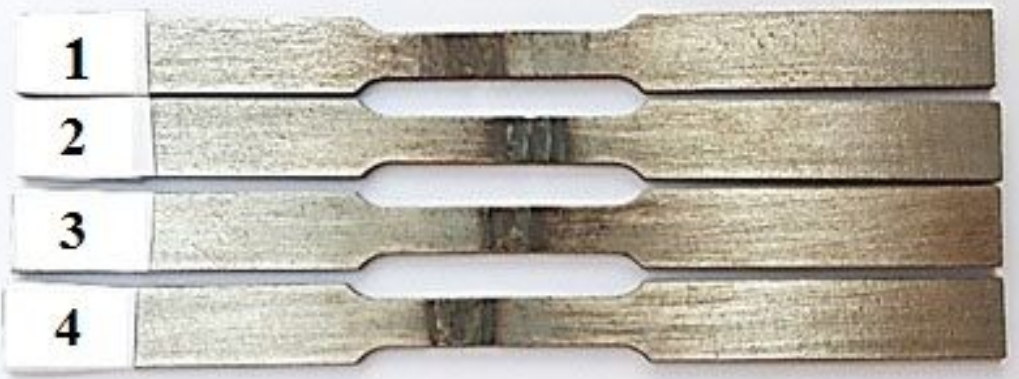

Figure 2

Welded tensile test specimens according to ASTME8. 


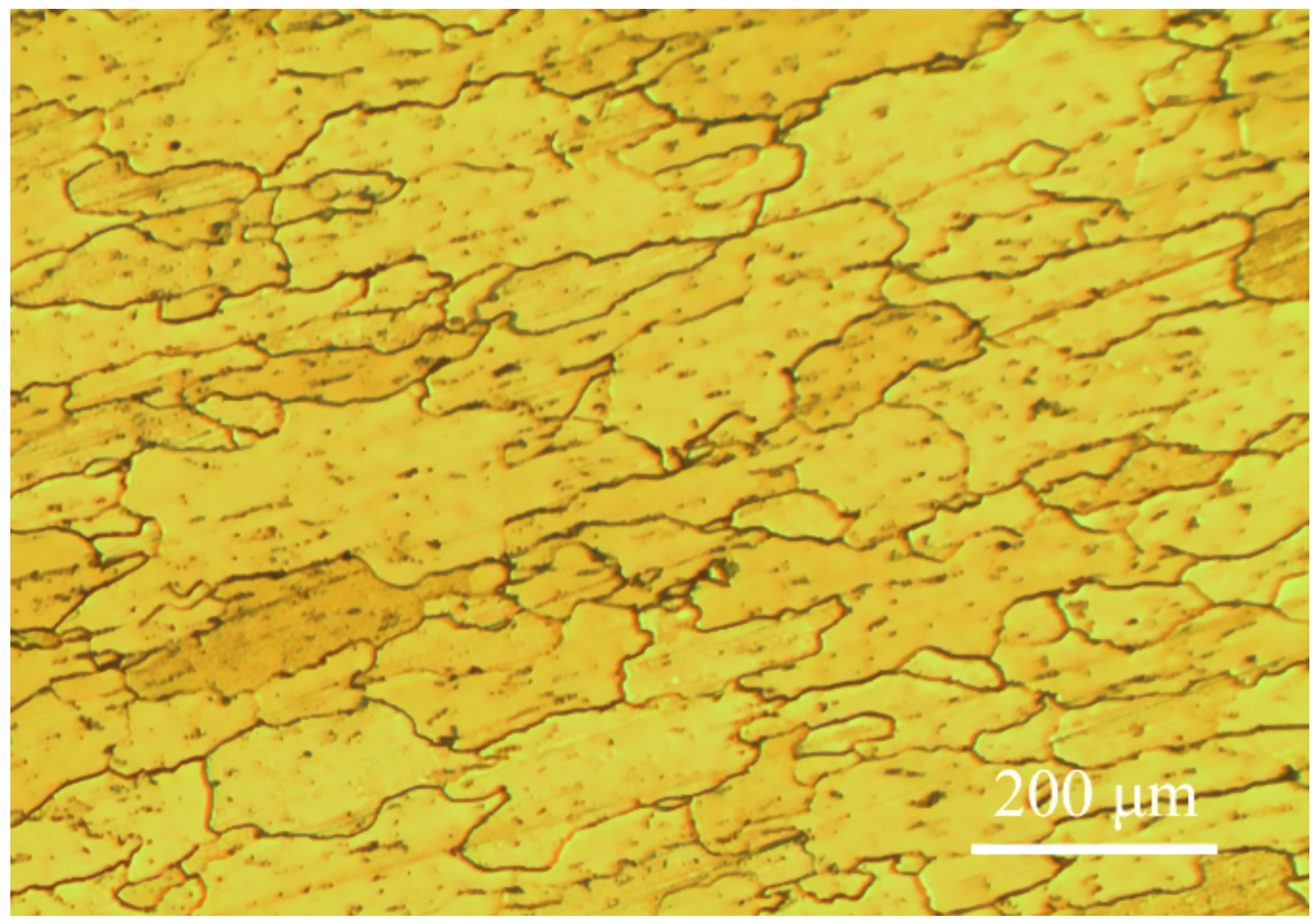

Figure 3

Microstructure of ST14 steel cross section (base metal). 


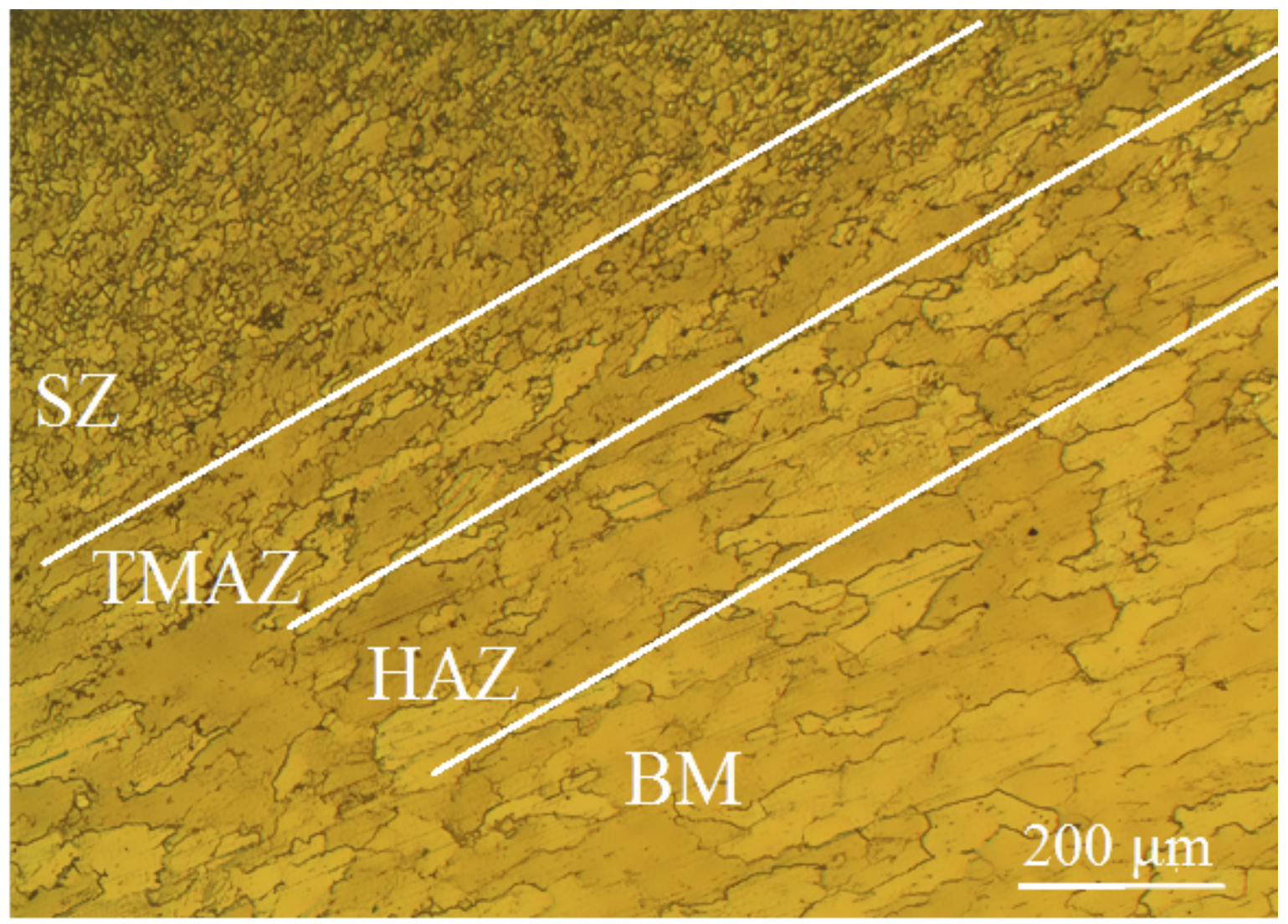

\section{Figure 4}

Microstructure of cross-section sample no (4).

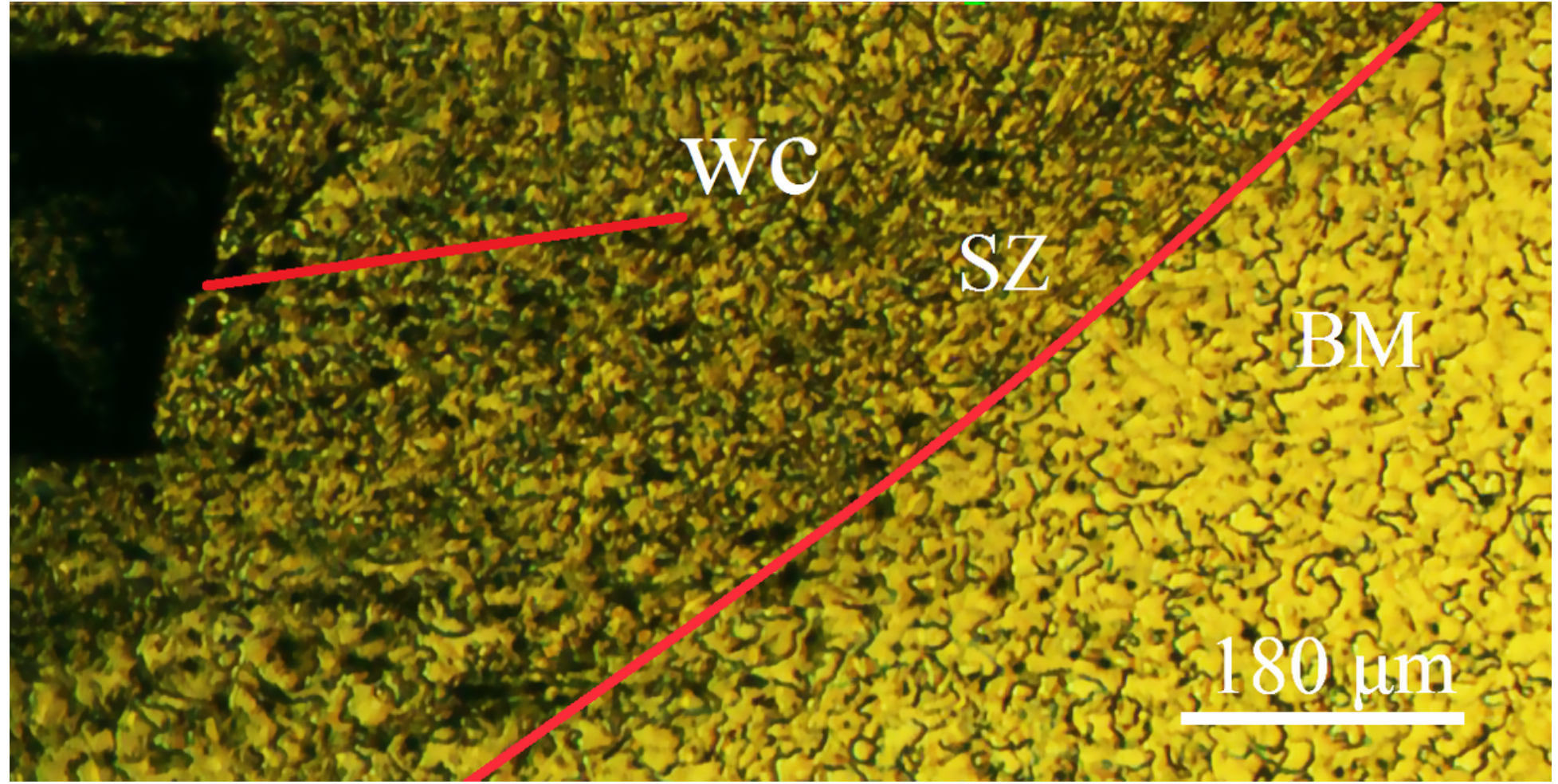

\section{Figure 5}


Microstructure of cross-section sample no (4).
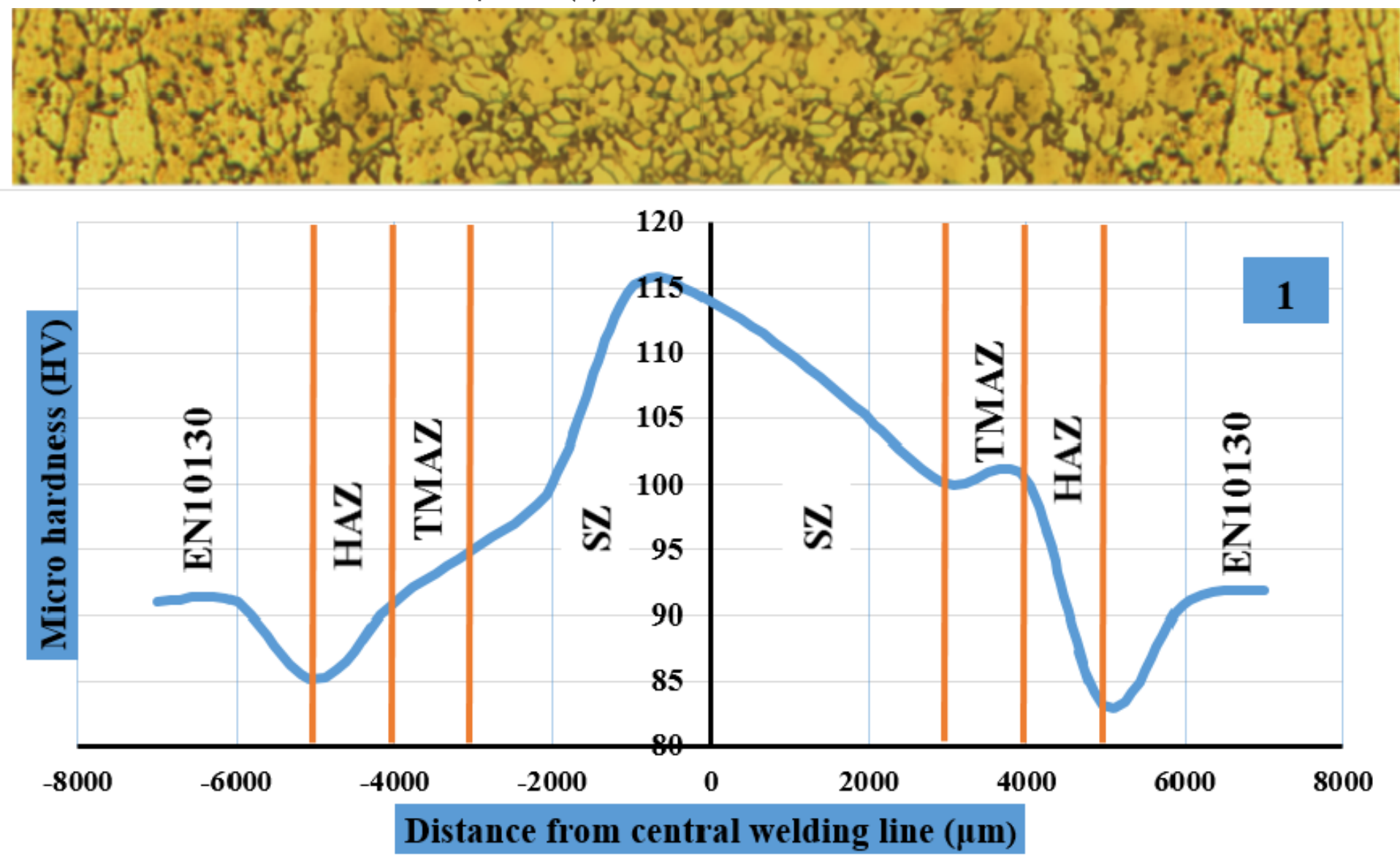

Figure 6

Hardness profiles of connection cross section Sample 1. 

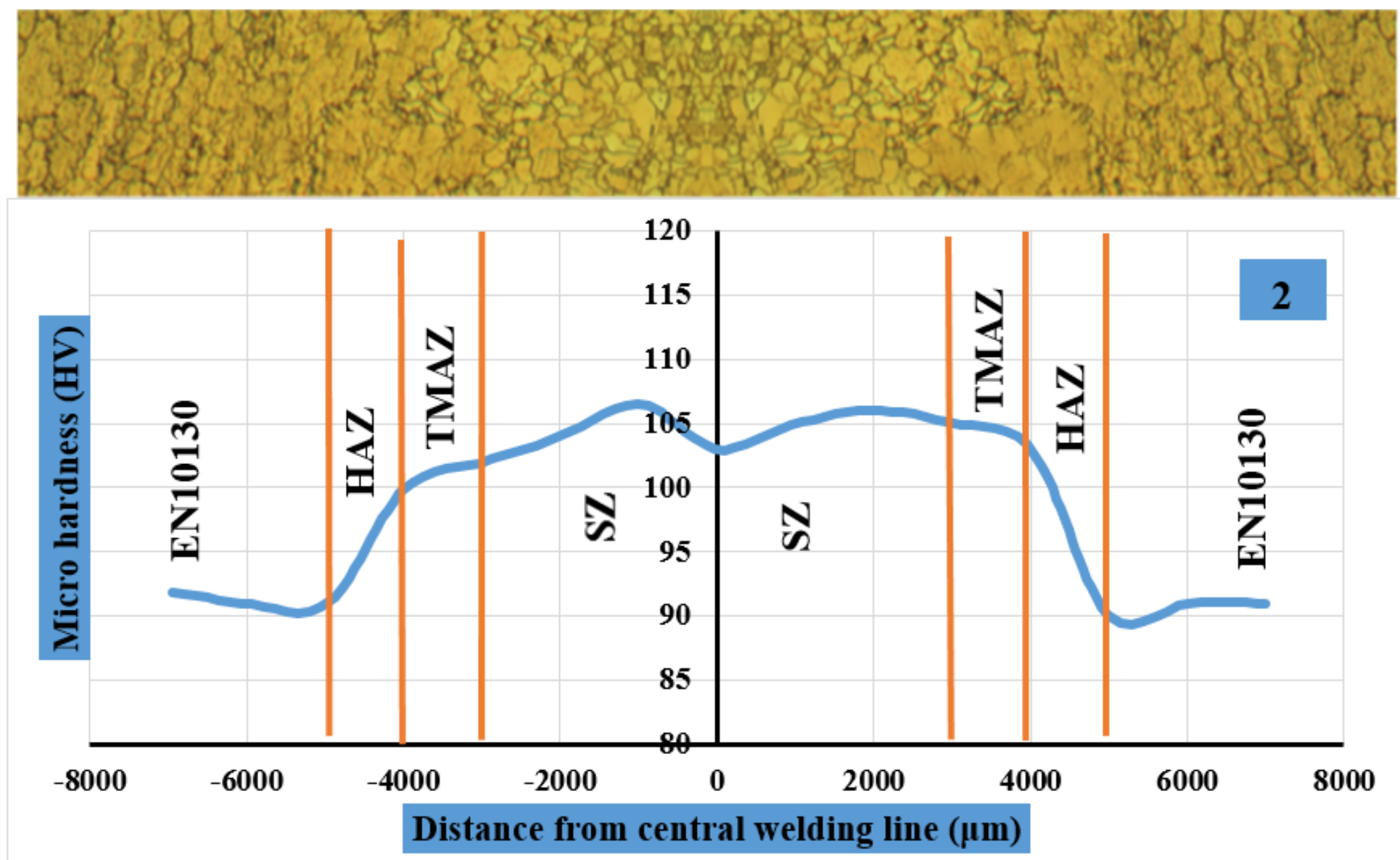

Figure 7

Hardness profiles of connection cross section Sample 2. 

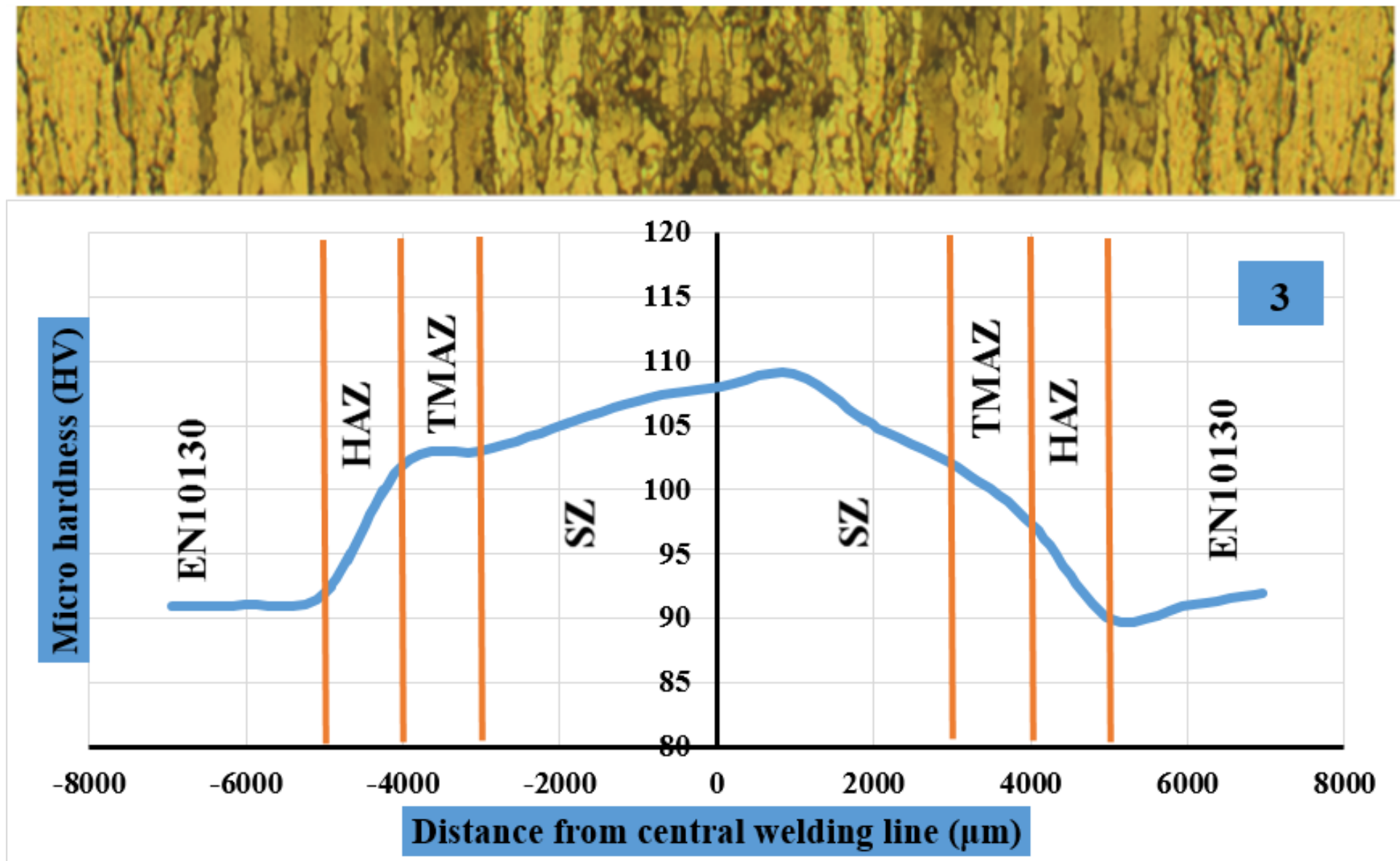

Figure 8

Hardness profiles of connection cross section Sample 3. 

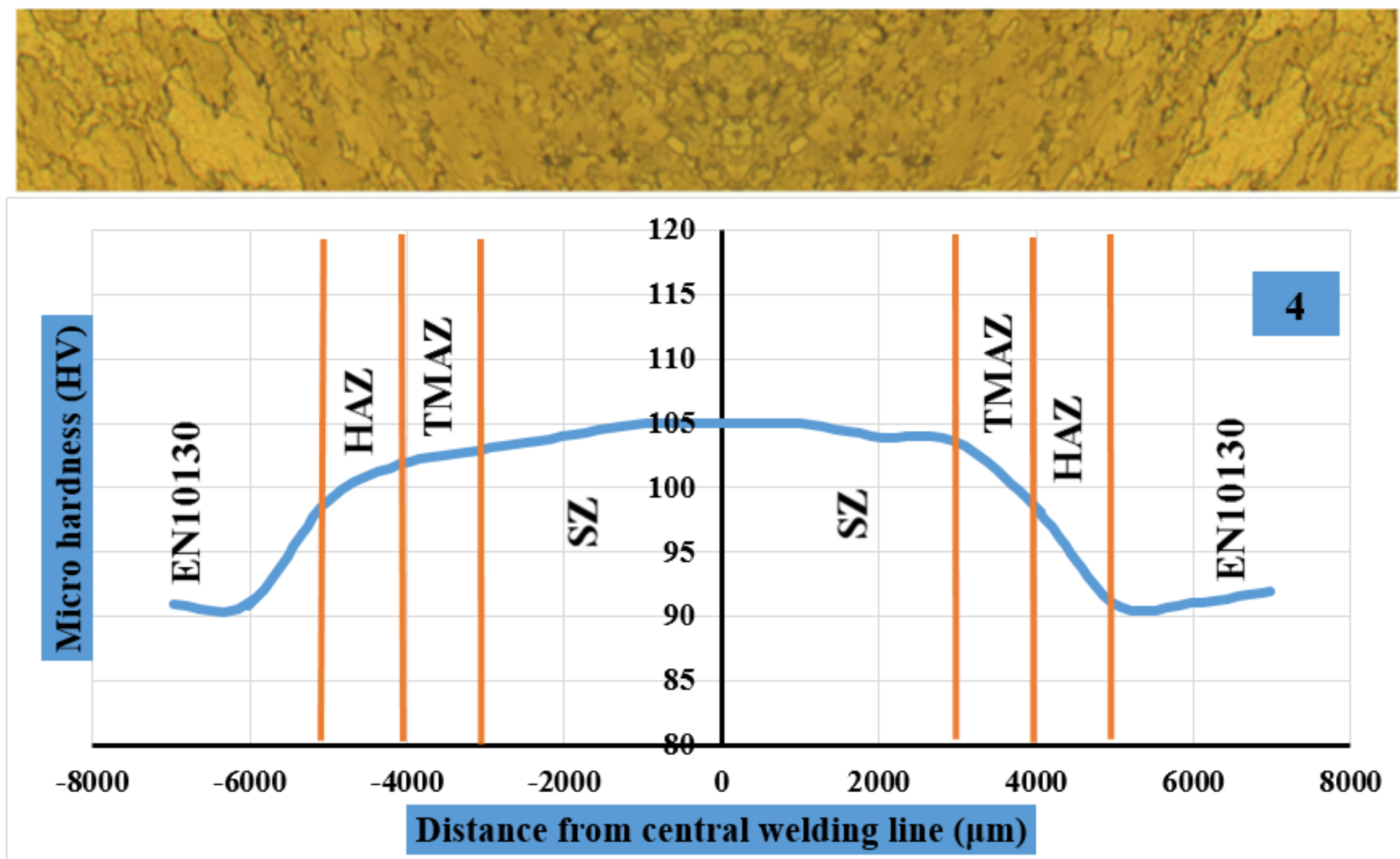

Figure 9

Hardness profiles of connection cross section Sample 4. 